\title{
Considering Curriculum, Standards, and Assessments in Mathematics Instruction
}

\author{
Veena Paliwal \\ University of West Georgia, Carrollton, USA
}

\begin{abstract}
This article synthesizes relevant research on a good elementary mathematics curriculum and an effective elementary mathematics instruction, while discussing various issues involved in curriculum review and developmentally appropriate instruction using mathematics standards. Research-based knowledge about good mathematics instruction has improved in recent years that facilitates in classifying mathematical skills students need to develop, as well as teaching strategies and instructional approaches that best support the development of these skills. The research-based knowledge using mathematics standards could serve as guidelines to reform elementary mathematics curricula and instruction, and could aid in preparation of future mathematics teachers in schools.
\end{abstract}

Keywords : mathematics assessments, mathematics curriculum, mathematics instruction, mathematics standards

\section{Introduction}

Good mathematics instruction involves good teachers, an effective and conducive math environment, and a curriculum that is research-based supported. Mathematics standards can serve as guidelines in reforming a mathematics curriculum. An understanding of a good mathematics instruction is needed to effectively carry out curriculum expectations that comprises knowledge of what gets taught, how it gets taught in the schools, what constitutes good teaching, and how to make conducive math environments that promote learning. Assessment provides a feedback on the effectiveness of a curriculum and helps in reforming instructional decisions. Recent reforms in the mathematics instructions provide guidelines in designing a curriculum and evaluating its effectiveness using relevant assessment techniques.

\section{Curriculum}

\section{What Gets Taught?}

Mathematics curriculum is the basis of what gets taught in the schools. A curriculum includes instructional content (syllabus), the methods employed (strategies), resources (books and other supporting material) supporting learning objectives, and the process for evaluating the attainment of intended curriculum objectives (assessment techniques). A good mathematics curriculum is coherent, focused on important mathematics, investigates thoroughly in depth into key concept and topic, and is well-articulated across the grades (Council of Chief State School Officers [CCSSO], 2010; National Council of Teachers of Mathematics [NCTM], 1989, 2000, 2006). A coherent mathematics curriculum has different mathematical ideas that are linked and build on

Veena Paliwal, Ph. D., assistant professor, Department of Mathematics, University of West Georgia. 
one another. For example, teaching multiplication by linking it with addition-a concept that is introduced before multiplication. Research-based curriculum could provide guidelines in finding important content and processes that should be the focus of mathematics instruction. An effective elementary mathematics curriculum is the one that focuses on depth instead of breadth. That is, it emphasizes the development of thorough understanding of the topics instead of teaching too many topics without any meaningful understanding. A long list of topics in curriculum expectations often results in teaching too many topics too quickly with far too little understanding. In designing a curriculum, the biggest challenge is to stay focused on important topics and not present a long list of disconnected expectations. The purpose of well-articulated curriculum is to help teachers guide students to strive for increasing level of finesse and depth of knowledge, and it presents challenging problems for students to learn increasing sophisticated ideas as they continue their study.

Designing a curriculum. An effective curriculum sets developmentally appropriate goals that are based on the developmental readiness of students while addressing individual differences in peoples' learning.

Learning trajectories. In designing a curriculum, an understanding of the learning path-how students develop an understanding of a topic-facilitates in setting developmentally appropriate goals to ensure appropriate learning of a concept. An understanding of learning trajectory and how children construct meaningful knowledge enables teachers to implement mathematics learning environment that is developmentally appropriate and effective (Baroody, Purpura, \& Reid, 2012). Learning path (trajectories) helps in answering several questions:

1. What are the goals of instruction?

2. Where do we start?

3. How do we know where to go next?

4. How do we get there?

Learning trajectory consists of a goal, a developmental progression, and instructional activities (Clement \& Sarama, 2004). To understand a topic (goal), students progress through several levels of thinking (developmental progression) that are supported by tasks and experiences (instructional activities). Goals and learning trajectories should explicitly lay out the big ideas and how to help students in making sense of them (Baroody, Purpura, \& Reid, 2012). Goals include big ideas which are predominant concepts that interconnect various concepts and procedures within a domain and across domains. Learning trajectories include several levels of thinking and sequential steps needed to achieve a goal (developmental progression), which children follow in developing understanding of a mathematical idea. Effective teachers use them to design instructional tasks from children's perspectives and help children to move through levels of understanding (Fuson, Carroll, \& Drueck, 2000). Instructional tasks are the activities that should match each level of children's developmental progression and should promote children's progression to the next level. For example, big ideas could be proficiently using counting sequence. Learning trajectory of achieving proficiency in counting consists of developmental progression of the following: no verbal counting, verbal counting with separate words not in order, counting to 10 with some object correspondence, one-to-one correspondence between counting words and objects for small sets, counting and understanding the cardinality (how many) of a bigger set.

Understanding individual differences in learning. There are individual differences in numerical abilities of pupils (Dowker, 2005). When developing a mathematical curriculum, individual differences in learning should be taken into account. Even before formal schooling numerical abilities are not unitary, but consist of many 
independent components. Numerical abilities can be grouped into different categories, but there are numerous subcomponents in each category. For example, procedural fluency consists of written, oral, and concrete calculation procedures and includes procedures applicable to different arithmetic operations. Individual children show discrepancies between different components of arithmetic. For example, solving word problems is generally considered more difficult than solving direct computational problems (for example, $3+9=$ ? or 54 $\div 6=$ ?).

However, there are some children who could efficiently do former, but have difficulty in executing the latter. Even in tasks that show high significant relationship, it is possible to find children who could perform one task without being able to perform the other. Numerical abilities are not a product of a single factor. In different sub-components, level of performance is influenced by multiple interacting factors: brain-based (innate and acquired), social, cultural, and educational. Early intervention that is based on the fact that arithmetic is based on various components and takes into account particular strengths and weaknesses of individuals can considerably ameliorate arithmetic difficulties. Using multiple approaches to solve a given problem is a way to account for the individual differences in learning.

Two views of learning. There are two prominent views of how learning takes place: rote memorization and meaningful memorization. In designing and implementing a curriculum, these views of learning facilitates in achieving the desired objectives. In rote memorization, the main idea is that learning requires continuous process of drill and repetitive practice until the combination forms an associative strength in memory. Rote memorization focuses on memorizing each concept separately. For example, each combination " $4+2=6$," "6 $-2=4$," and " $6-4=2$ " need to be memorized separately. In rote memorization, learning is viewed independent of arithmetic regularities, such as the addition-subtraction complement principle (If $4+2=6$, then $6-2=4$ or $6-4=2$ ) that focuses on procedural and conceptual knowledge (Shrager \& Siegler, 1998; Siegler \& Araya, 2005). In meaningful memorization, learning is viewed as the outcome of meaningful understanding that consists of organized framework of understandable facts, principles, and processes to promote learning of a concept (e.g., Brownell, 1935; National Mathematics Advisory Panel [NMAP], 2008). Children meaningfully understand mathematics instruction by making connections through the process of assimilation and integration. Children assimilate (interpret and understand) new information by connecting it with their existing knowledge. For example, to understand subtraction expression a teacher might connect it with children's existing addition knowledge (for the subtraction problem " $4-3=$ ?," connecting it with children's existing knowledge of addition and thinking what needs to be added to 3 to get 4 , i.e., $3+$ ? $=4$ ). The process of integration involves connecting two previously unrelated ideas. For example, understanding that multiplication is the same as repeated addition $(3 \times 5=$ ? and $5+5+5=$ ? are the same), or division and repeated subtraction are the same $(15 \div 5=3$ as $15-5=10,10-5=5$, and $5-5=0)$ results in deeper understanding of both operations addition and multiplication, or division and subtraction. Understanding how two concepts are related results in a thorough understanding of both concepts as pupils can use their understanding of previously known concepts (i.e., addition or subtraction) to understand a newly introduced concept (i.e., multiplication or division). Allowing students to construct meaningful knowledge should allow them opportunities to use assimilation and integration for effective mathematics instruction and learning. Indeed, a study in California revealed that memorization without understanding does not help in combination fluency (Henry \& Brown, 2008). In another study, students with meaningful instruction explain the algorithm, had higher retention rates, and used information more adaptively than the control group (Brownell \& Moser, 1949). 
How it gets taught? The effectiveness of a curriculum relies on crucial process of teaching it. To understand a best approach in mathematics instruction, an understanding of different approaches to instruction is needed.

Different approaches to instruction. The four approaches to instruction are:

1. Skills approach - based on dualistic philosophy, the aim of instruction is basic skills mastery where teacher is the authoritative source of knowledge and emphasis is on direct instruction and drill;

2. Conceptual approach — based on pluralistic philosophy, the aim of instruction is mastery of basic skills with understanding (content-oriented) where teacher is strong-armed guide and emphasis is on guided discovery and imposition of concrete models;

3. Investigative approach — based on instrumentalism, the aim of instruction is mastery of basic skills with understanding (process-oriented) where teacher is a gentle guide who emphasizes a variety of purposeful, meaningful, and inquiry-based tasks, and children invent their own concrete models and symbolic procedures;

4. Problem-solving approach-based on extreme relativism, the aim of instruction is to foster mathematical thinking where teacher provide a little or no feedback and emphasis is on unstructured discovery, and rich and complicated projects (Baroody \& Dowker, 2003).

The four approaches to instruction mainly differ in whether emphasize skills or concepts, i.e., to teach for skills (procedural knowledge) or for concepts (conceptual knowledge). With skill-based instruction, focus of instruction is on developing computational skills and recall of arithmetic facts. With the conceptual-based approach, focus in on developing conceptual understanding through meaningful instruction (assimilation and integration).

\section{Good Teaching is Key}

Student learning is based on the quality of the implementation of a teaching practice (Grouws, 2004). The most debated issues in mathematics teaching are discussed below.

Teaching for conceptual vs. procedural knowledge. Conceptual and procedural knowledge can benefit from the acquisition and application of one another. Research has revealed that the conceptual understanding and procedural skills develop side by side. They are continually intertwined and facilitate each other (CCSSO, 2010; Fuson, 2004, Kilpatrick, Swafford, \& Findell, 2001; NMAP, 2008). For example, solving near-doubles problems using doubles (for example, solving $6+7=$ ? using $6+6=12$ ) requires understanding of both skills and concepts. Solving a problem " $6+7=$ ?" using doubles understanding $(6+6=12)$ requires conceptual understanding that " $6+7$ " should be one more than " $6+6$ " as 7 is one more than 6 , so " $6+7$ " equals 13 (one more than 12). Skill mastery is required to recall the appropriate double combination that could help in solving near-doubles and to execute the entire computation properly. Just the skill approach does not yield to mastery of a concept, but skill with understanding allows students to use known information adaptively. For example, an understanding that " $n+1$ " or " $1+n$ " is the number after $n$ in the counting sequence $(10+1$ is 11$)$ allows pupils to compute " $43,235+1$ " as 43,236 without any prior practice.

Student-centered vs. teacher-centered teaching. Researchers have long debated whether the student-centered or teacher-centered teaching technique is effective in promoting mathematics learning. Research has not supported one view over the other in teaching (Clement \& Sarama, 2012; NMAP, 2008). With the teacher-based approach, the teacher plays the central role of information transmitter, and main focus of instruction is on developing computational skills and recall of facts. With the student-centered approach, 
students are encouraged to arrive at a solution and to consider more than one-way of solving a problem. It is important to note that the teacher plays an important and central role in both approaches of instruction. With the teacher-centered approach, the teacher is the central authority and students are supposed to follow rules and procedures as instructed by the teacher. Also, with the student-centered approach, the teacher plays the role of the person who encourages students to work in groups and share mathematical ideas with each other in the group. In case of disagreement or conflict, the teacher welcomes mathematical discourse, helps students to work towards a consensus, encourages students while working in groups to build on their partner's idea, and engages students in a mutual process of understanding and making sense of mathematics.

Explicit instruction vs. discovery learning. Explicit instruction involves directing pupil's attention to a specific concept using a structured environment rather than an exploratory model (Clement \& Sarama, 2012). The aim of explicit instruction is to achieve specific leaning outcomes by providing step-by-step direction to achieve desired objectives. Discovery leaning is based on constructivist theory of knowledge where meaningful learning takes place through interaction between experiences and ideas. Pupils learn through problem-solving by using provided resources. Students play role of an active learner, and they are in the control of the instruction and have the responsibility of learning where facts and skills are not taught directly. Discovery learning facilitates students to develop conceptual understanding by using reasoning and problem-solving in discovering knowledge that emerges from experience with problems, not through transmission from teachers or books.

Both explicit and discovery learning approaches are crucial in instruction. In some contexts, instruction that explicitly addresses the concepts is more effective. For example, teaching a relatively new concept. Explicit instruction has also been found to help students with a math disability by using a didactic form of instruction where facts and skills are presented directly rather than indirectly (Fuchs et al., 2008). Also, assisted instruction with explicit explanation, examples, scaffolding, and feedback does make a difference compared to unassisted instruction (Alfieri, Brooks, Aldrich, \& Tenenbaum, 2010). Discovery learning was effective in another study where at-risk first graders, in both structured and unstructured discovery learning, improved on " $n+1$ " combinations (Baroody, 1987). The effectiveness of an approach is dependent on the content of the instruction and developmental readiness of the students (Baroody, Purpura, \& Reid, 2012). For example, explicit instructions on basic counting strategies, such as concrete-counting-all, helped young children in learning the strategy (e.g., Baroody, 1987; Fuson \& Secada, 1986), but the same was not true for more advanced counting strategy, such as abstract-counting-all (Baroody, 1984; Baroody, Tiillikainen, \& Tai, 2006). On the other hand, direct instruction on modeling abstract-counting-on helped third graders to learn the strategy (Fuchs et al., 2009). Developmental readiness of the students might be the reason why direct instruction have helped promote counting-on in the Fuchs et al.'s (2009) study, but not in the Baroody (1987) and Fuson and Secada's (1986) study.

Which approach to choose? The effectiveness of a teaching method depends on the learning goal and one method might be more appropriate than other in achieving a learning goal (Hiebert \& Grouws, 2007). An effective mathematics instruction is balanced and it focuses on both conceptual and procedural understanding, and balances between teacher- and student- centered, or explicit instruction and discovery learning approaches depending on the content of the instruction (Kilpatrick, Swafford, \& Findell, 2001). The most effective teaching method cannot have the same strategy for each learning goal and a shift among a mix of teaching methods is more effective in achieving the goal of the lesson. 


\section{Standards}

An approach to instruction is based on the goal of the instruction. The standards lay out what students need to know and to be able to execute in each grade level, and the techniques to assess students' understanding of the expected knowledge. The goals of a mathematics instruction in the United States (U.S.) were first laid out by NCTM. NCTM $(1989 ; 2000 ; 2006)$ presented a new vision of mathematics instruction because of dissatisfaction with the traditional skill approach. These reports described general goals and content that should be included in school mathematics in Grades pre-kindergarten (Pre-K-12). The specific content, including both skills and concepts, to be taught is presented in the report in grade-bands (Pre-K-2, 3-5, 6-8, and 9-12). The document proposed changes in the content of school mathematics and more importantly on the way mathematics is taught in schools. The goals set by NCTM regarding the content of mathematics instruction included conceptual understanding, problem solving, and reasoning strategies. NCTM stressed on making mathematics instruction relevant (purposeful), conceptually supported (meaningful), and process-based (inquiry-based).

For teaching mathematics, the NCTM $(1989 ; 2000 ; 2006)$ had recommended a shift from a traditional instructional approach to an approach that built the "mathematical power" of children. "Mathematical power" has these components:

1. Positive disposition - understanding and believing that mathematics makes sense, and having confidence in tackling challenging problems;

2. Understanding mathematics - appreciating the applications of mathematics in everyday life, understanding how two facts are mathematically connected, and linking concepts and skills;

3. Mathematical inquiry — engaging children in making and testing assumptions, finding existing patterns (inductive reasoning), problem solving, and logical reasoning (deductive reasoning);

4. Procedural fluency - ability to apply their knowledge to solve problems within mathematics and other disciplines (National Research Council [NRC], 2009).

These teaching standards are not intended to be a complete checklist of specific concepts, skills, and behaviors that must be followed in the classrooms. They are illustrations or indicators of judging appropriate and valuable aspects of mathematics instruction. They furnish guidance to all those who are working towards improving teaching and provide direction for moving towards excellence in teaching.

Impact of the NCTM standards. In the U.S., during the 1990s, many states and school districts developed and modified their own standards and curriculum in accordance with NCTM's recommendations. NCTM recommendations were also used as guidelines by National Science Foundation (NSF) supported programs for designing instructional materials (Senk \& Thompson, 2003). Pointing on NCTM standards, Lappan and Briars (1995) wrote that standards took into account children's mathematical knowledge from their experiences, and the importance of understanding that mathematical knowledge was dependent on how it was learnt. These views were consistent with what Dewey $(1916$; 1933) expressed about the relevance of context and social interaction in learning.

There is little research available to determine the features of the standards that have most impact on classroom practice. A case study by Ferrini-Mundy and Schram (1997) revealed that pedagogical features, such as cooperative learning or discussion were more readily taken by teachers compared to the mathematics-content features, such as emphasis on the process of arriving at an answer rather than the answer itself. 
Criticism of the NCTM standards. The critics often misinterpret NCTM standards as advocating the problem-solving approach (discovery learning) at the expense of skill mastery. In particular, the critics of the standards are concerned that emphasizing on the process of obtaining an answer, rather than an answer itself, will lead to decline in basic skills (Senk \& Thompson, 2003). Some critics of the reform emphasized that students must first develop computational skills before they develop conceptual understanding of mathematics. Other critics (a minority) do not believe conceptual understanding is a necessary goal of instruction. The critics claim that skills need to be mastered and practiced, using time-tested conventional methods until they become automatic. Students should spend time practicing skills rather than in investigations inventing alternatives, or justifying more than a way to solve a problem.

Math wars. The debate over traditional mathematics and reform mathematics philosophy and curricula, which differs significantly in approach and content, was so strident that it has been labeled as "math wars" (Schoenfeld, 2004). Those who oppose these standards believe NCTM standards promote laissez-faire problem solving approach, whereas supporters of NCTM standards believe that those who oppose these standards are supporters of authoritarian skill approach. The moderates in these two camps of the "math wars" recognize the need to reform mathematics instruction. Moderates recommend similar goals, but they propose different approaches for achieving these goals. One camp of moderates advocates the semi-direct conceptual approach, with some problem solving and reasoning in the instruction. Moderates in proponents of NCTM standards are generally closer to the semi-indirect investigative approach.

Recent developments. In 2000, the NCTM released the Principles and Standards for School Mathematics (PSSM). The report was seen as more balanced than the original 1989 standards. This resulted in some calming, but not an end to the dispute. Two recent reports have led to considerably more cooling of the "Math wars." In 2006, NCTM released its Curriculum Focal Points, a report of topics considered central for mathematics from Pre-K-8. Curriculum Focal Points focused on specific guidelines to look for in a grade. This report was seen by many as a compromise position. In 2006, the Bush's administration established the NMAP with the goal of improving mathematics achievement in schools. The panel investigated and summarized the scientific evidence related to the teaching and learning of mathematics and gave a report in March, 2008 and concluded all-encompassing recommendations that instruction should be entirely "student-centered" or "teacher-directed" are not supported by research (NMAP, 2008). The panel called for an end to the "math wars" by concluding that conceptual understanding, computational and procedural fluency, and problem-solving are equally important and reinforces mutual development.

Common core state standards. The most recent initiative to improve mathematics and English language arts education in the U.S. is the common core state standards (CCSSO, 2010), which clearly laid out the content for students in Grades K-12. Common core state standards aims to have consistent educational standards across the states in the U.S. and to prepare students graduating from high school for entering credit-bearing courses at two- or four- year college programs or for joining the workforce. The standards only described the content students need to master at each grade level and skills students need to acquire to be successful at career or college-level education. Individual school district can choose curricula-based on the standards. The standards were released on June 2010 and were adopted by 44 of the 50 states in the U.S. and District of Columbia. Federal grants, such as "Race to the Top," provided initiatives for the states to adopt the standards.

Math standards. The standards were a response to the American curriculum criticism as "a mile wide and an inch deep," i.e., incoherent curriculum teaching too many topics without mastering. The common core state 
standards offer a kind of mathematics instruction comparable to top achieving nations where a few topics are taught each year before moving to more advanced mathematics instruction.

The mathematics standards consist of Standards for Mathematical Practice and Standards for Mathematical Content. There were eight Standards for Mathematics Practice, which described how students need to be taught so that parents and mathematics educator can support students' learning:

1. To make sense of problems and persevere in solving them;

2. To reason abstractly and quantitatively;

3. To construct viable arguments and critique the reasoning of others;

4. To model with mathematics;

5. To use appropriate tools strategically;

6. To attend to precision;

7. To look for and make use of structure;

8. To look for and express regularity in repeated reasoning.

Standards for mathematical content. Mathematics content for the students is described in a number of domains for each grade. For each domain, there are several standards for each standard in the domain. For example, there are four common domains for Grades K-5: (a) operations and algebraic thinking; (b) number and operations in base 10; (c) measurement and data; and (d) geometry. In addition to these kindergarten also includes the domain counting and cardinality and Grades 3 to 5 also include the domain number and operations-fractions.

Response to the standards. Common core state standards have been criticized by many as an effort by the federal government to have a national curriculum. The supporters of the standards, such as educational analysts from the Thomas B. Fordham Institute (TBFF) determined that the common core standards are clearly superior to those currently in use in 39 states in math and 37 states in English. For 33 states, the common core is superior in both math and reading. National Education Association (NEA) reported that the common core state standards are supported by $76 \%$ of its teacher members.

\footnotetext{
Assessment

An assessment is a measure of attainment of stated instructional objectives by monitoring students' progress and evaluating students' achievement. Good mathematics instruction has effective assessment techniques that access its success in promoting learning of the concepts. Primary aim of an assessment is based on the assumption that people possess measurable and identifiable attributes (e.g., knowledge, skills, understanding, etc.) and it is possible to identify and examine peoples' attribute (Morgan, 1999). This assumption relies on positivist approach - every rationally admissible assertion can be verified - more applicable in mathematics than other disciplines where responses can be clearly classified as true and false with no room for uncertainty. An assessment provides information about student learning and performance that can be used to improve education. An assessment provides answers to two basic questions for instructions:

1. Have students learned at the end of a program or a course?

2. Have students successfully achieved what was expected from them (the goals of the instruction)?

An assessment includes various techniques, such as class discussion, an exam, or a mini-teaching project to discover pupils' knowledge to refine instruction, to name a few.

According to the NRC (2009), formative assessment refers to assessment for learning and it enables teachers to know children's position on a learning trajectory (e.g., level of understanding and thinking), and use
} 
that information to plan or improve instruction. Formative assessment draws from the use of observation, task, and personal interview. The information about a child's current behavior, thinking, and learning promotes the implementation of effective teaching methods and a positive learning environment, and positive relationships between teachers and students promotes high quality early childhood education. Formative assessments provide immediate feedback to both teachers and students about the process of learning and thus facilitates in teachers in evaluating their teaching effectiveness and students approach to learning. A summative assessment refers to assessment of learning and it provides a summary of development of a learner at a particular time. That is, the extent to which instructional and learning goals have met (NRC, 2009). Summative assessment happens later in the learning path. Some examples of summative assessments are: state assessments, district benchmarks, end-of-chapter tests, end-of-unit exams, and semester finals. Summative assessments happen later in the learning path and are the tools to help evaluate the effectiveness of a program or curriculum

NCTM (2000) provided standards for mathematics assessment as: (a) reflect the mathematics that all students need to know and be able to do; (b) enhance mathematics learning; (c) promote equity; (d) be an open process; (e) promote valid inferences about mathematics learning; and (f) be a coherent process. Formative and summative tools of assessment for areas specified by the common core state standards is developed by two consortiums, partnership for the assessment of readiness for college and career (PARCC) and smarter-balanced assessment consortium (SBAC). The states adopting the common core standards will opt for one of these assessment instruments. Some states have chosen which of the consortia they will work with, while others are still considering their plans. Assessment in mathematics education mainly assesses students' proficiency of the standards of mathematical practices (CCSSO, 2010), which aligns with the process standards in NCTM's PSSM. The assessment of students' mastery of the standards for mathematical practice can also be included in state assessment plans by states that have not adopted the common core state standards.

\section{Conclusion}

Reform in elementary mathematics curricula and instruction must ensure that the three-curriculum, standards, and assessment - must be aligned and coherent for an effective mathematics instruction. The author visualizes that future mathematics instruction where young children are actively engaged to be on the road of mathematical proficiency should include these reform efforts. The topics are taught and learned in a setting that ensures that reasoning, problem-solving, connections, communication, and conceptual understanding are all developed at the same time along with procedural fluency (Kilpatrick, Swafford, \& Findell, 2001). The goal of instruction is meaningful learning where focus of instruction is on developing understanding. In this instructional environment, teachers act as learning facilitators, and students are active participants for purposeful learning. Fuson (1992) described future mathematics classrooms as, places where children construct meanings from mathematical concepts, words, and written marks and carry out, discuss, and justify solution procedures for mathematical situations (p. 268). The author believes this is what constitutes good mathematics instruction.

\section{References}

Alfieri, L., Brooks, P. J., Aldrich, N. J., \& Tenenbaum, H. R. (2010). Does discovery-based instruction enhance learning? Journal of Educational Psychology, 103(1), 1-18.

Baroody, A. J. (1984). The case of Felicia: A young child's strategies for reducing memory demands during mental addition. Cognition and Instruction, 1(1), 109-116. 
Baroody, A. J. (1987). The development of counting strategies for single-digit addition. Journal for Research in Mathematics Education, 18, 141-157.

Baroody, A., \& Dowker, A. (2003). The development of arithmetic concepts and skills: Constructing adaptive expertise. Studies in mathematics thinking and learning. Mahwah, N.J.: Erlbaum.

Baroody, A. J., Purpura, D. J., \& Reid, E. (2012). Comments on learning and teaching early and elementary mathematics. In J. Carlson, \& J. Levin (Eds.), Psychological perspectives on contemporary educational issues (Vol. 3). Charlotte, N.C.: Information Age Publishing.

Baroody, A. J., Tiilikainen, S. H., \& Tai, Y. (2006). The application and development of an addition goal sketch. Cognition and Instruction, 24, 123-170.

Brownell, W. A. (1935). Psychological considerations in the learning and the teaching of arithmetic. In D. W. Reeve (Ed.), The teaching of arithmetic (Tenth yearbook, National Council of Teachers of Mathematics, pp. 1-50). New York, N.Y.: Bureau of Publications, Teachers College, Columbia University.

Brownell, W. A., \& Moser, H. E. (1949). Meaningful vs. mechanical learning: A study in grade III subtraction. Durham, N.C.: Duke University Press.

Clements, D. H., \& Sarama, J. (2004). Hypothetical learning trajectories. Mathematical Thinking and Learning, 6(2).

Clements, D. H., \& Sarama, J. (2012). Learning and teaching early and elementary mathematics. In J. Carlson \& J. Levin (Eds.), Psychological perspectives on contemporary educational issues (Vol. 3). Charlotte, N.C.: Information Age Publishing.

Council of Chief State School Officers (CCSSO) (2010). Common core state standards: Preparing America's students for college and career. Retrieved from http://www.corestandards.org/

Dewey, J. (1916). Democracy and education. New York, N.Y.: Macmillan.

Dewey, J. (1933). How we think. Lexington, M.A.: Heath.

Dowker, A. (2005). Individual differences in arithmetic: Implications for psychology, neuroscience, and education. Hove: Psychology Press.

Ferrini-Mundy, J., \& Schram, T. (1997). The recognizing and recording reform in mathematics education project. Journal for Research in Mathematics Education (Monograph series 8). Reston, V.A.: National Council of Teachers of Mathematics.

Fuchs, L. S., Fuchs, D., Powell, S. R., Seethaler, P. M., Cirino, P. T., \& Fletcher, J. M. (2008). Intensive intervention for students with mathematics disabilities: Seven principles of effective practice. Learning Disability Quarterly, 31(2), 79-92.

Fuchs, L., Powell, S. R., Seethaler, P. M., Cirino, P. T., Fletcher, J. M., Fuchs, D., \& Hamlett, C. L. (2009). The effects of strategic counting instruction, with and without deliberate practice, on number combination skill among students with mathematics difficulties. Learning and Individual Differences, 20(2), 89-100

Fuson, K. C. (1992). Research on whole number addition and subtraction. In D. A. Grows (Ed.), Handbook of research on mathematics teaching and learning (pp. 243-275). New York, N.Y.: MacMillan.

Fuson, K. C. (2004). Pre-K to Grade 2 goals and standards: Achieving 21 st-century mastery for all. In D. H. Clements, J. Sarama, \& A-M DiBase (Eds.), Engaging young children in mathematics, (pp. 105-148). Mahwah, N.J.: Lawrence Erlbaum associates.

Fuson, K. C., Carroll, W. M., \& Drueck, J. V. (2000). Achievement results for second and third graders using the standards-based curriculum everyday mathematics. Journal for Research in Mathematics Education, 31, 277-295.

Fuson, K. C., \& Secada, W. G. (1986). Teaching children to add by counting-on with one-handed finger patterns. Cognition and Instruction, 3(3), 229-260.

Grouws, D. A. (2004). Mathematics. In G. Cawelti (Ed.), Handbook of research on improving student achievement. Arlington, V.A.: Educational Research Service.

Henry, V. J., \& Brown, R. S. (2008). First-grade basic facts: An investigation into teaching and learning of an accelerated, high-demand memorization standard. Journal for Research in Mathematics Education, 39(2), 153-183.

Hiebert, J. C., \& Grouws, D. A. (2007). The effects of classroom mathematics teaching on students' learning. In F. K. Lester, Jr. (Ed.), Second handbook of research on mathematics teaching and learning (Vol. 1, pp. 371-404). New York, N.Y.: Information Age Publishing.

Kilpatrick, J., Swafford, J., \& Findell, B. (2001). Adding it up: Helping children learn mathematics. Washington, D.C.: National Academy Press.

Lappan, G., \& Briar, D. (1995). How should mathematics be taught? In I. M. Carl (Ed.), Prospect for school mathematics (pp. 131-156). Reston, V.A.: National Council of Teachers of Mathematics. 
Morgan, C. (1999). Assessment in mathematics education: A critical social research perspective. In J.Portela (Ed.), Actas do ix seminário de investigação em educação matemática (Proceedings of the IX Mathematics Education Research Seminar) (pp. 5-23). Guimarães: Associação de Professores de Matemática.

National Council of Teachers of Mathematics (NCTM) (1989). Curriculum and evaluation standards for school mathematics. Reston, V.A..

National Council of Teachers of Mathematics (NCTM). (2000). Principles and standards for school mathematics: Standards 2000. Reston, V.A..

National Council of Teachers of Mathematics (NCTM). (2006). Curriculum focal points for prekindergarten through Grade 8 mathematics: A quest for coherence. Reston, V.A..

National Mathematics Advisory Panel (NMAP). (2008). Foundations for success: The final report of the National Mathematics Advisory Panel. Washington, D.C.: U.S. Department of Education, Office of Planning, Evaluation, and Policy Development.

National Research Council (NRC). (2009). Mathematics in early childhood: Learning paths toward excellence and equity. Washington, D.C.: National Academy Press.

Olander, H. T. (1931). Transfer of learning in simple addition and subtraction. Elementary School Journal, 31, 427-437.

Schoenfeld, A. H. (2004). The math wars. Educational Policy, 18, 253-286.

Senk, S. L., \& Thompson, D. R. (2003). Standards-based school mathematics curricula: What are they? What do students learn? Mahwah, N.J.: Lawrence Erlbaum Associates.

Shrager, J., \& Siegler, R. S. (1998). SCADS: A model of children's strategy choices and strategy discoveries. Psychological Science, 9(5), 405-410. doi: 10.1111/1467-9280.00076

Siegler, R., \& Araya, R. (2005). A computational model of conscious and unconscious strategy discovery. In R. Kail (Ed.), Advances in child development and behaviour (Vol. 33, pp. 1-42). New York: Academic Press.

Thorndike, E. L. (1922). The psychology of arithmetic. New York, N.Y.: Macmillan. 